\title{
Fine mapping analysis confirms and strengthens linkage of four chromosomal regions in familial hypospadias
}

\author{
Cilla Söderhäll1,2,9, Izabella Baranowska Körberg ${ }^{3,4,9}$, Hanh TT Thai ${ }^{3}$, Jia $\mathrm{Cao}^{3}$, Yougen $\mathrm{Chen}^{3}$, Xufeng Zhang ${ }^{3}$, \\ $\mathrm{Zu}$ Shulu $^{3}$, Loes FM van der Zanden ${ }^{5}$, Iris ALM van Rooij ${ }^{5}$, Louise Frisén ${ }^{6}$, Nel Roeleveld ${ }^{5,7}$, Ellen Markljung ${ }^{3}$, \\ Ingrid Kockum ${ }^{6}$ and Agneta Nordenskjöld ${ }^{\star 3,8}$
}

Hypospadias is a common male genital malformation and is regarded as a complex disease affected by multiple genetic as well as environmental factors. In a previous genome-wide scan for familial hypospadias, we reported suggestive linkage in nine chromosomal regions. We have extended this analysis by including new families and additional markers using non-parametric linkage. The fine mapping analysis displayed an increased LOD score on chromosome 8q24.1 and 10p15 in altogether 82 families. On chromosome 10p15, with the highest LOD score, we further studied AKR1C2, AKR1C3 and AKR1C4 involved in steroid metabolism, as well as KLF6 expressed in preputial tissue from hypospadias patients. Mutation analysis of the AKR1C3 gene showed a new mutation, c.643G $>$ A (p.(Ala215Thr)), in a boy with penile hypospadias. This mutation is predicted to have an impact on protein function and structure and was not found in controls. Altogether, we homed in on four chromosomal regions likely to harbor genes for hypospadias. Future studies will aim for studying regulatory sequence variants in these regions.

European Journal of Human Genetics (2015) 23, 516-522; doi:10.1038/ejhg.2014.129; published online 2 July 2014

\section{INTRODUCTION}

Hypospadias is a common congenital malformation in boys, characterized by incomplete fusion of the urethral folds, abnormal opening of the urethra and different degrees of curvature of the penis. Although hypospadias most often occurs as an isolated defect, it can be associated with cryptorchidism, bifid scrotum and micropenis, especially when severity of hypospadias is pronounced. The frequency of hypospadias ranges from 0.3 to $0.8 \%$ among male live births in Europe, Asia and North America. ${ }^{1-3}$ In Sweden, the incidence of hypospadias is $0.3 \%$ since the beginning of the $1970 \mathrm{~s}$ according to the annual Swedish Malformation Registry. ${ }^{1,4}$

Hypospadias is considered to be a complex disorder caused by the interplay between environmental factors and effects of multiple genes. It is well established that hypospadias is associated with determinants, such as low birth weight, placenta insufficiency, high maternal BMI and parental subfertility. ${ }^{5-7}$ Several observations suggest that hypospadias is under genetic influence. Approximately 7-9\% of fathers with a son with hypospadias have the same malformation and the recurrence risk for a brother of an affected boy has been described to be as high as $17 \%{ }^{8,9}$ Familial clustering of hypospadias without a monogenic inheritance pattern is observed in $\sim 7 \%$ of all cases, indicating a multifactorial inheritance of the malformation. ${ }^{10,11}$ Familial hypospadias, in contrast to many other complex disorders, usually has a milder phenotype, probably because the malformation also affects fertility. ${ }^{7,10,12}$ In addition, some families have been described with an autosomal dominant or recessive pattern of inheritance. ${ }^{13-15}$ Hypospadias is also a feature in more than one hundred genetic syndromes (www.ncbi.nlm.nih.gov/omim).

The molecular events that affect normal male genital development have been extensively studied during the last decades. Recent studies in mice revealed possible involvement of genes in early genital tubercle development, such as sonic hedgehog $(s h h)$, fibroblast growth factors 8 and 10 ( $f g f 8$ and $f g f 10$ ), homeobox A13 and D13 (hoxa13 and hoxd13) and ephrin (Eph). ${ }^{16-19}$ Nevertheless, the main pathway driven by testosterone is crucially important. Testosterone is produced in Leydig cells in the testes and is converted to dihydrotestosterone (DHT) in the target tissues, the external genitalia and the prostate gland. DHT binds to the androgen receptor (AR), and forms a complex that can subsequently bind to the androgen response element (ARE) on DNA resulting in a masculinization of the phallus and prostate. Thus, defects in the androgen metabolism, such as mutations in the $17 \beta$ hydroxysteroid dehydrogenase type 3 (HSD17B3) gene, the $A R$ gene and the 5-alpha reductase (SRD5A2) gene, can increase hypospadias risk. ${ }^{20-23}$ The finding of estrogen receptors in the male reproductive tract during development raises the possibility that estrogens may also influence the risk for hypospadias. ${ }^{24}$

${ }^{1}$ Department of Molecular Medicine and Surgery, Center for Molecular Medicine, Karolinska Institutet, Stockholm, Sweden; ${ }^{2}$ Department of Biosciences and Nutrition, Karolinska Institutet, Stockholm, Sweden; ${ }^{3}$ Department of Women's and Children's Health, Center for Molecular Medicine, Karolinska Institutet CMM 02, Karolinska University Hospital, Stockholm, Sweden; ${ }^{4}$ Department of Clinical Genetics, Karolinska University Hospital, Stockholm, Sweden; ${ }^{5}$ Department for Health Evidence, Radboud University Nijmegen Medical Centre, Nijmegen, The Netherlands; ${ }^{6}$ Department of Clinical Neuroscience, Center for Molecular Medicine, Karolinska Institutet, Stockholm, Sweden; ${ }^{7}$ Department of Pediatrics, Radboud University Nijmegen Medical Center, Nijmegen, The Netherlands; ${ }^{8}$ Department of Pediatric Surgery, Astrid Lindgren Children Hospital, Karolinska University Hospital, Stockholm, Sweden

*Correspondence: Professor A Nordenskjöld, Department of Women's and Children's Health, Center for Molecular Medicine, Karolinska Institutet CMM 02, Karolinska University Hospital, Stockholm SE-171 76, Sweden. Tel: +46 8517764 08; Fax: +46 8517736 20; E-mail: agneta.nordenskjold@ki.se

${ }^{9}$ These authors contributed equally to this work.

Received 14 November 2013; revised 27 May 2014; accepted 30 May 2014; published online 2 July 2014 
Currently, four hypospadias genes have been identified, namely the Mastermind-like Domain-containing 1 gene (MAMLD1/CXorf6), the Activating Transcription Factor 3 (ATF3) gene, the Diacylglycerol kinase kappa $(D G K K)$ gene and most recently the basonuclin 2 (BNC2) gene. ${ }^{25-28}$

In our search for hypospadias candidate genes, we previously performed a genome-wide linkage scan in 69 families with at least two affected family members. ${ }^{29}$ Multipoint LOD scores above 1.44 were consistent with suggestive linkage, which was observed in four regions on chromosomes 2, 9 and 10. Five additional regions with weaker evidence of linkage $(P$-value $<0.01)$ were found. Altogether, nine chromosomal regions were identified (1q23, 2p11, 6q25, 8p21-22, $8 \mathrm{q} 24.1,9 \mathrm{q} 21-22,10 \mathrm{p} 15,10 \mathrm{q} 21$ and 18q21). In order to home in on candidate genes for hypospadias, we added more families and performed fine mapping in 82 families using 85 microsatellite markers in these nine candidate regions.

\section{MATERIALS AND METHODS}

\section{Subjects}

Fine mapping. In our previous study, a genome-wide linkage scan was performed in 69 families with at least two affected family members. ${ }^{29}$ For the current fine mapping analysis, 13 additional families including eleven Swedish (46 individuals) and two Iranian families (eight individuals) were recruited. In total, 363 individuals were genotyped, of which 180 were affected. The distribution of the degree of relationship of all 96 affected relative pairs is listed in Table 1. Pedigrees are available on request.

Candidate gene analyses. Candidate genes were selected in chromosome 10 p15 (LOD score $=1.67, P<0.02$ ). Three genes of the AKR1C subfamily (AKR1C2, AKR1C3 and AKR1C4) as well as the KLF6 gene were chosen for mutation screening because of their function in the testosterone metabolism and expression in genital skin in hypospadias cases. ${ }^{30,31}$

Sequence analyses. One affected individual from each of the 17 families linked to the 10p15 region (LOD score >1.0) was sequenced for AKR1C3 (NM_003739.5), AKR1C4 (NM_001818.3 and NG_031872.1) and KLF6 (NM_001300 and NG_012277.1). In addition, sequencing of these three genes was performed in affected boys $(n=95)$ without a familiar history of hypospadias and controls $(n=95)$. For AKR1C2 (NM_001354.5 and NG_031852), sequencing of the coding exons (exons 3-11) was performed in discordant sib pairs from 13 families showing linkage in the 10p15 region. Variants have been submitted to the gene variant database, dbSNP (URL: http://www.ncbi.nlm.nih.gov/SNP/) with submission ID 1059797.

Association analyses. For the association analyses, we included an extended Swedish cohort consisting of 310 hypospadias patients and 901 controls (713 anonymous voluntary blood donors and 188 placental samples from healthy infants from Karolinska University Hospital, Stockholm, Sweden), as well as 797 Dutch hypospadias cases and their parents collected in the AGORA (Aetiologic research into Genetic and Occupational/environmental Risk factors

Table 1 Degree of relationship in the affected relative pairs (including relative pairs added for fine mapping analysis)

\begin{tabular}{lccc}
\hline & Total & Swedish & Middle Eastern \\
\hline Affected sib pairs & $65(9)$ & $51(7)$ & $14(2)$ \\
Affected half-sib pairs & $4(1)$ & $2(1)$ & 2 \\
& & & \\
Proband with affected relative (degree) & $6(1)$ & $6(1)$ & 0 \\
Second & $17(2)$ & $16(2)$ & 1 \\
Third & 4 & 4 & 0 \\
Fourth & & & \\
\hline
\end{tabular}

for Anomalies in children), data- and biobank of the Radboud University Nijmegen Medical Centre, Nijmegen, The Netherlands.

Ethics statement. All participants and/or their parents gave written informed consent for participation in the study. The Regional Committee on Research Involving Human Subjects Arnhem-Nijmegen approved the AGORA protocol, and the Ethics Committee at the Karolinska University Hospital approved this study.

\section{Methods}

Microsatellite genotyping. Eighty-five microsatellite markers were genotyped in the nine chromosomal regions (1q23, 2p11, 6q25, 8p21-22, 8q24.1, 9q21-22, 10p15, 10q21 and 18q21) identified in the previously published genome-wide linkage scan. ${ }^{29}$ The markers were selected from the integrated maps of the Marshfield Medical Research Foundation (http://research.marshfieldclinic.org/ genetics) and the deCode database. ${ }^{32}$ The average intermarker distance across the fine-mapped regions was $2.5 \mathrm{~cm}$. The mean success rate for included markers was $84 \%$. Microsatellite genotyping was performed as described earlier. ${ }^{29}$ The resulting genotypes were analyzed using Genescan2.1 and Genotyper2.0 softwares (Applied Biosystems, Foster City, CA, USA). All genotypes were checked manually.

Sequencing. Exons and flanking intronic sequences (to identify any splice site mutations) were amplified using exon-specific primers. Primers and amplification conditions are available upon request. Direct sequencing was performed on both strands using Big-Dye terminator v3.1 (Applied Biosystems) and run on an ABI3130 Sequencer (Applied Biosystems). Sequencing primers were the same as used in the PCR amplification. The sequencing reactions were carried out according to the manufacturer's recommendations. Chromatograms were analyzed using SeqScape v3.7 (Applied Biosystems).

SNP genotyping. Five polymorphisms in the $5^{\prime}$ end of the AKR1C3 gene (rs1937845;T >C, rs10904415;C > T, rs3763676;T >C, rs12529;G $>C$ and rs7741;A $>$ G) were genotyped in the hypospadias patients and controls of the extended Swedish cohort and the Dutch AGORA cohort. Genotyping was performed using TaqMan allelic discrimination assays according to the manufacturer's recommendations (Applied Biosystems).

\section{Statistical analysis}

Family structure was examined by comparing the expected and observed average identity-by-state of genotyped markers in all sib pairs using the zGenstat 1.128 software (Henric Zazzi, unpublished). Genotypes were checked for Mendelian inconsistencies using the same program. All inconsistencies were re-analyzed and incompatibilities were resolved unambiguously or individuals and/or pedigrees were excluded from linkage analyses. As hypospadias is restricted by gender, males with hypospadias were defined as affected, whereas other males with normal phenotypes were marked as unaffected and females were coded as unknown. Linkage analysis was performed using the information of all markers across the chromosomal regions showing linkage in the previous study, thus including markers used in the genome-wide linkage scan and markers for fine mapping, on the whole set of 82 families with 96 affected pairs including two separate subgroups (Swedish and Middle Eastern origin). A non-parametric model was used, as the pedigrees showed mixed patterns of disease inheritance and the true underlying inheritance model was unknown. For every marker, single-point and multipoint linkage analyses were obtained using the Allegro software. ${ }^{33}$ Corresponding $P$-values were interpreted according to Lander and Kruglyak, ${ }^{34}$ and $P$-values were estimated using the formula, $P(\mathrm{LOD})=0.5 \times\left(\chi^{2}{ }_{1}>2 \ln 10 \times \mathrm{LOD}\right)$.

For the association analyses in the Swedish cohort, single marker and multiple-marker association tests were performed using Haploview. ${ }^{35}$ The $P$-value was corrected for multiple testing by performing 10000 permutations using Haploview. Differences in haplotype frequencies between cases and controls were calculated using the $\chi^{2}$ test and the Fisher's exact test with the Statistica 7.0 software (StatSoft, Tulsa, OK, USA). For the Dutch case-parent triads, we used the transmission disequilibrium test. ${ }^{36}$ 
In silico analysis of gene variants

To predict the possible impact of an amino-acid substitution on the structure and function of a protein, the Polyphen (Polymorphism Phenotyping) and SIFT (Sorting Intolerant From Tolerant) programs were used. ${ }^{37,38}$

\section{RESULTS}

Fine mapping

Our previously published genome-wide linkage scan in 69 families revealed evidence for suggestive linkage on chromosomes $2 \mathrm{p} 11$, $9 \mathrm{q} 21-22,10 \mathrm{p} 15$ and $10 \mathrm{q} 21$. In addition, we could present weaker linkage on chromosomes 1q23 and 6q25 in the subgroup of 58 Swedish families and on chromosomes $8 \mathrm{q} 24$ and $18 \mathrm{q} 21$ in the subgroup of 11 families with Middle Eastern origin. ${ }^{29}$ In this study, with the inclusion of additional markers and families, we confirmed and strengthened the evidence of linkage for chromosome regions 8q24.1 and 10p15 (Figure 1 and Table 2). The highest LOD scores (multipoint 1.67 and single point $1.5, P<0.02$ ) were detected for chromosome 10p15 (LOD $>1,15-21 \mathrm{~cm}$ ). In subgroup analysis, this locus on 10 p 15 showed linkage $(\operatorname{LOD}=1.14, P<0.04)$ in the 69 Swedish families. On chromosome 8q24.1, the linkage analysis of the total material showed a multipoint LOD score of $1.32 \quad(P<0.03$; LOD $>1,124-138 \mathrm{~cm})$. In subgroup analyses, this locus showed linkage in the group of families originating from Middle Eastern countries (multipoint $\mathrm{LOD}=1.04, P<0.03$; Table 2). In addition, in the subgroup of Swedish families, multipoint LOD scores greater than 1 was also found on $1 \mathrm{q} 23(\mathrm{LOD}=1.27, P<0.02)$. In the group of families originating from Middle Eastern countries, also the linkage peak on 18q21 (multipoint LOD $=1.1, P<0.03$ ) was confirmed. The strategy of the analyses has been summarized in a flowchart (Figure 2).

\section{Candidate gene analyses in $10 \mathrm{p} 15$}

Candidate genes were selected from the most significantly linked region 10p15. Three genes of the AKR1C subfamily (AKR1C2, AKR1C3

Table 2 Summary of all linkage peaks for fine mapping with maximum multipoint LOD score greater than 1 obtained in linkage analysis in all families and in ethnic subgroups

\begin{tabular}{|c|c|c|c|c|}
\hline Multipoint & Chromosomal region & $\angle O D$ & $\mathrm{P}$-value & Marker \\
\hline \multirow[t]{2}{*}{ All } & $8 q 24.1$ & 1.32 & $<0.03$ & D8S514 \\
\hline & $10 p 15$ & 1.67 & $<0.02$ & D10S1779 \\
\hline \multirow[t]{2}{*}{ Middle Eastern } & $8 q 24.1$ & 1.04 & $<0.03$ & D8S514 \\
\hline & $18 q 21$ & 1.1 & $<0.03$ & D18S858 \\
\hline \multirow[t]{2}{*}{ Swedish } & 1q23 & 1.27 & $<0.02$ & D1S518 \\
\hline & 10p15 & 1.14 & $<0.04$ & D10S1412 \\
\hline
\end{tabular}

The marker with the highest single-point LOD score in each peak is listed.
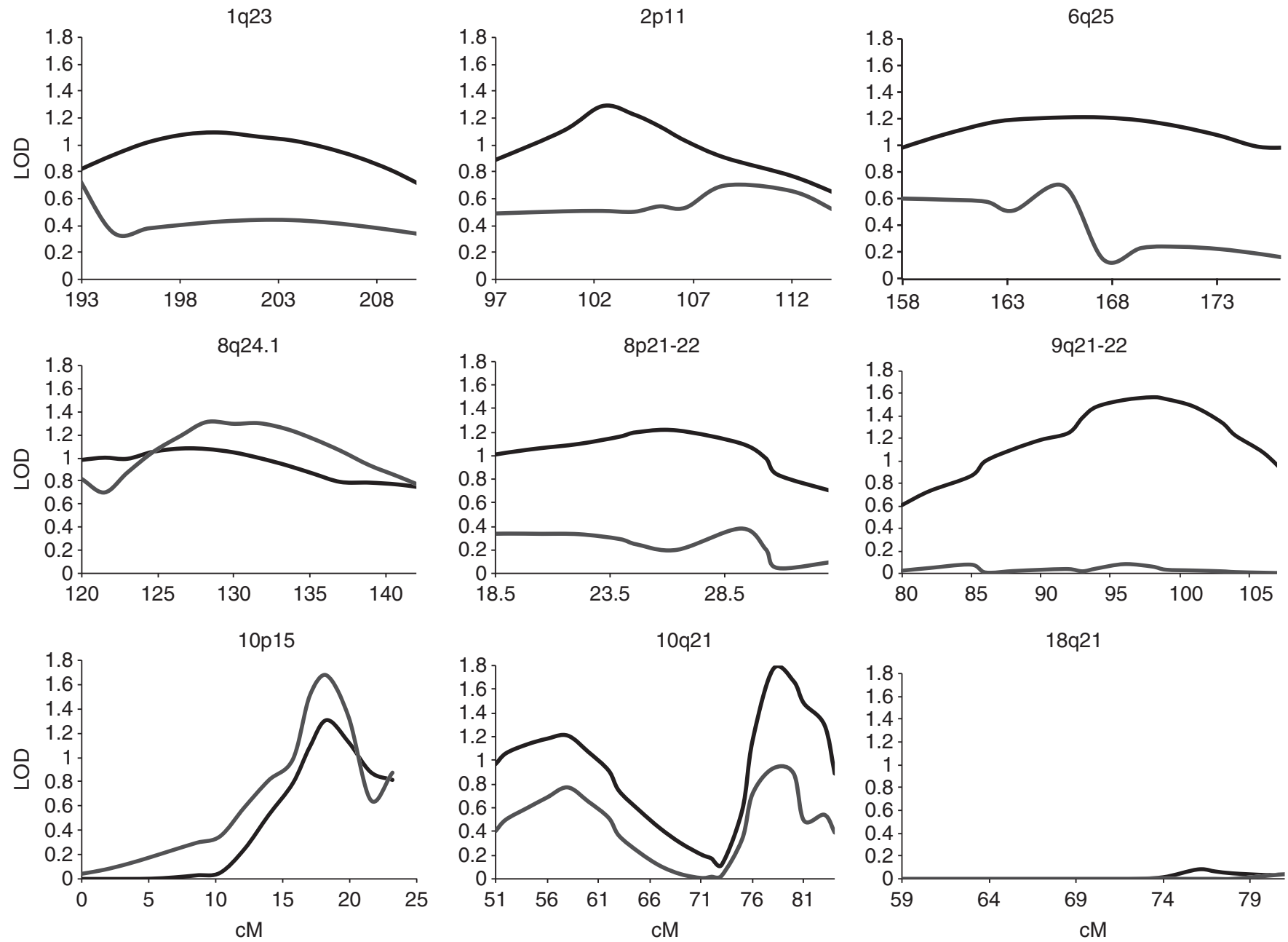

Figure 1 The multipoint LOD score in the initial genome-wide linkage scan (69 families, black line) and the current fine mapping study (82 families, gray line). LOD score is shown on the $y$ axis and $c M$ from the pter on $x$ axis. 
and $A K R 1 C 4)$ as well as the KLF6 gene were chosen for sequencing analyses because of their function in the testosterone metabolism and expression in genital skin in hypospadias cases. ${ }^{30,31}$

\section{The AKR1C3 gene}

Sequencing of the exons of AKR1C3 revealed sequence variants in several patients (Table 3). One heterozygous variant in exon 6,

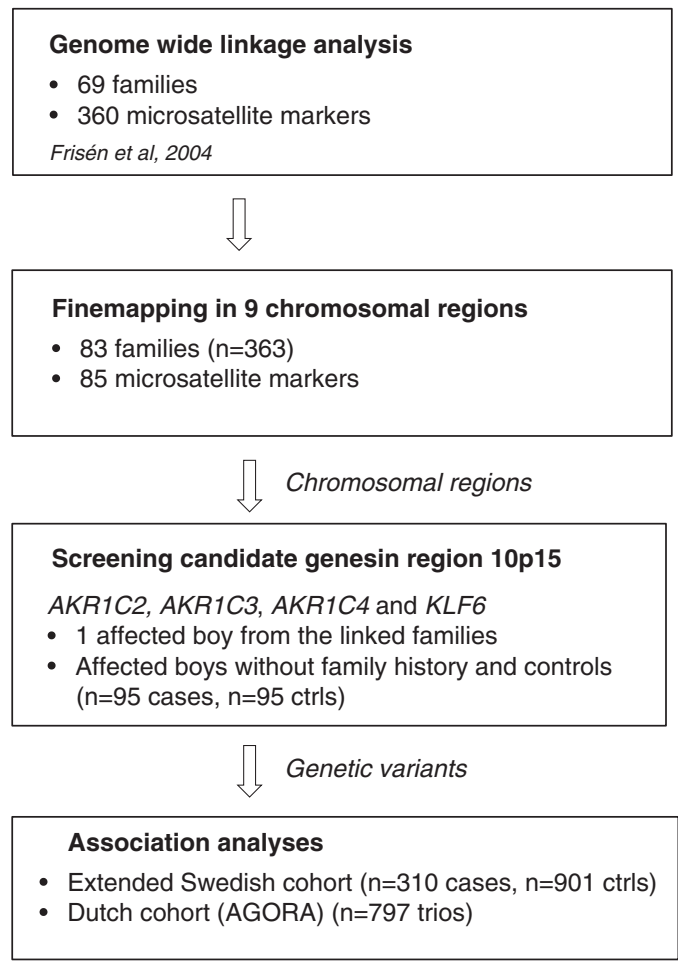

Figure 2 Flowchart describing the strategy of this study.
c.643G $>$ A p.(Ala215Thr), was detected in a boy with penile hypospadias. This sequence variant was not present in any of the 95 control individuals, is conserved in several mammals (Pan troglodytes, Macaca mulatta, Bos Taurus, Mus musculus and Rattus norvegicus) and has not been described previously. In order to further elucidate the role of $\mathrm{p}$.(Ala215Thr) on the structure and function of the AKR1C3 protein, the Polyphen and SIFT programs were used. At this position in the AKR1C3 protein sequence, any change from Alanine (a non-polar amino acid) to a polar residue, such as Threonine, was predicted to affect protein function.

Five known gene variants (rs3763676;T $>C$, rs12529;G $>C$, rs7741;A>G, rs11551177; $A>G$ and rs12387;G>A) were found in both sporadic and familiar cases. Three polymorphisms (rs3763676;T $>$ C, rs12529;G $>C$ and rs7741;A $>$ G) showed statistically significant different allele frequencies between cases (familial and sporadic) and controls (Table 3). This finding led us to perform a haplotype analysis of these three SNPs in which three haplotypes were identified: AGG, GCA and ACG. However, none of these showed any significant association with hypospadias (Table 4). We also examined the associations of rs3763676; $>$ C, rs12529; G $>C$ and rs7741;A $>\mathrm{G}$ and two promoter SNPs ( $\mathrm{rs} 1937845 ; \mathrm{T}>\mathrm{C}$ and rs10904415;C > T) with hypospadias in the extended Swedish and Dutch cohorts, where no statistically significant associations were detected either (Table 5).

\section{The AKR1C4 gene}

Two genetic variants were detected by sequencing the AKR1C4 gene (Table 3). A heterozygous variant in intron $4, c .447+9 \mathrm{~T}>\mathrm{G}$ (rs201441444), was detected in one boy with scrotal hypospadias and none of the 95 control individuals (Table 3). A coding variant, c. $435 \mathrm{C}>\mathrm{G}$, changes the amino acid from Serine to Cysteine in codon 435 and has previously been reported as a polymorphism (rs3829125;C $>\mathrm{G}$ ). However, no differences in allele frequencies between cases and controls were detected.

Table 3 Genetic variants in the $A K R 1 C 3$ and $A K R 1 C 4$ genes detected by sequencing analysis

\begin{tabular}{|c|c|c|c|c|c|c|c|}
\hline Gene & Gene variant & rs number & Location & Allele & Cases \% (N) & Control \% (N) & $\mathrm{P}$-value \\
\hline \multirow[t]{15}{*}{$A K R 1 C 3$} & c. $1-138 \mathrm{~T}>\mathrm{C}$ & rs3763676 & 5'UTR & $A / A$ & $50(55)$ & $45^{a}$ & $P<0.05$ \\
\hline & & & & $A / G$ & $40(44)$ & 42 & \\
\hline & & & & $\mathrm{G} / \mathrm{G}$ & $10(11)$ & 13 & \\
\hline & c. $15 \mathrm{C}>\mathrm{G}(\mathrm{p} .(\mathrm{His} 5 \mathrm{Gln}))$ & rs12529 & Exon 1 & $\mathrm{C} / \mathrm{C}$ & $38(42)$ & $33^{a}$ & $P<0.05$ \\
\hline & & & & $\mathrm{C} / \mathrm{G}$ & $41(46)$ & 54 & \\
\hline & & & & $\mathrm{G} / \mathrm{G}$ & $21(23)$ & 13 & \\
\hline & c. $90 \mathrm{G}>\mathrm{A}$ & rs7741 & Exon 2 & $\mathrm{G} / \mathrm{G}$ & $52(58)$ & $44^{\mathrm{a}}$ & $P<0.05$ \\
\hline & & & & $G / A$ & $38(42)$ & 43 & \\
\hline & & & & $A / A$ & $10(12)$ & 13 & \\
\hline & c. $230 A>G(p .(G l u 77 G l y))$ & rs1 1551177 & Exon 2 & $A / A$ & $86(95)$ & $86(81)^{b}$ & \\
\hline & & & & $A / G$ & $14(16)$ & $14(13)$ & \\
\hline & c. $311 \mathrm{G}>\mathrm{A}$ & rs12387 & Exon 3 & $\mathrm{~A} / \mathrm{A}$ & $72(79)$ & $73^{a}$ & \\
\hline & & & & $A / G$ & $25(28)$ & 22 & \\
\hline & & & & $\mathrm{G} / \mathrm{G}$ & $3(3)$ & 5 & \\
\hline & c.643G $>$ A (p.(Ala215Thr)) & & Exon 6 & $\mathrm{G} / \mathrm{A}$ & 1 & $\mathrm{O}^{\mathrm{b}}$ & \\
\hline \multirow[t]{4}{*}{$A K R 1 C 4$} & c. $435 \mathrm{C}>\mathrm{G}$ (p.(Ser145Cys)) & rs3829125 & Exon 4 & $\mathrm{C} / \mathrm{C}$ & $20(22)$ & $25^{\mathrm{a}}$ & \\
\hline & & & & $\mathrm{G} / \mathrm{C}$ & $78(78)$ & 73 & \\
\hline & & & & $\mathrm{G} / \mathrm{G}$ & $2(2)$ & $(2)$ & \\
\hline & c. $447+9 \mathrm{~T}>\mathrm{G}$ & rs201441444 & Intron 4 & $\mathrm{~T} / \mathrm{G}$ & 1 & $\mathrm{O}^{\mathrm{b}}$ & \\
\hline
\end{tabular}

Bold letters show a novel mutation found in the AKR1C3 gene.

aFrom the NCBI database (www.ncbi.nlm.nih.gov), HapMap-CEU.

bFrom sequencing of 95 controls. 


\section{The AKR1C2 gene}

Sequencing of coding exons (exons 3-11) of the AKR1C2 gene (NM_001354.5 and NG_031852) in discordant sib pairs from 13 families showing linkage in the $10 \mathrm{p} 15$ region revealed no coding variants. Three previously described SNPs were observed ( rs13945;C > T, rs145355870;A $>\mathrm{G}$ and rs56259037;C $>\mathrm{T}$ ) but did not show a statistically significant association with hypospadias.

\section{The Kruppel-like factor 6 gene (KLF6)}

Sequencing analysis of the KLF6 gene revealed four genetic variants (c. $496 \mathrm{C}>\mathrm{T}$, c. $800+21 \mathrm{C}>\mathrm{T}$, c. $800+34 \mathrm{G}>\mathrm{A}$ and c. $\left.{ }^{*} 62 \mathrm{G}>\mathrm{A}\right)$ present only in affected boys and not in the 95 controls. The previously undescribed heterozygous variant c.496C $>\mathrm{T}$ (p.(Pro166Ser)) was found in one boy with scrotal hypospadias and chordee. In addition, he carried a 45,X/46,XY mosaicism. The variants c. $800+21 \mathrm{C}>\mathrm{T}$, present in two patients, and c. $800+34 \mathrm{G}>\mathrm{A}$, found in one patient, are both intronic genetic variants. One variant located in the $3^{\prime} \mathrm{UTR}$, c. ${ }^{\star} 62 \mathrm{G}>\mathrm{A}$, was detected in one patient. None of these variations were found in the 95 controls; thus, they might represent private variants. Other gene variants found in this gene, rs11544694;A $>C$, rs3750861;C $>\mathrm{T}, \quad$ rs35835052; C $>\mathrm{T}, \quad$ c.603G $>$ A, c. ${ }^{*} 46 \mathrm{~A}>\mathrm{T}$, rs17731;A $>\mathrm{G}$ and $\mathrm{rs} 1050046 ; \mathrm{C}>\mathrm{T}$, were present in the same frequency among cases and controls. Homology analysis of the KLF6 nucleotide and protein sequence indicated that all of these gene variants are conserved.

\section{DISCUSSION}

In order to elaborate on genes contributing to hypospadias, we performed a linkage analysis by adding 85 microsatellite markers in already linked chromosomal regions and extended our previously examined material with 13 new families with at least two affected individuals in each family. Increased LOD scores on chromosomes $8 \mathrm{q} 24.1$ and $10 \mathrm{p} 15$ were observed in the extended material. Interestingly, these regions showed evidence of linkage in different subgroups in the previous study: the 10p15 region in the Swedish subgroup and the $8 \mathrm{q} 24.1$ region in the Middle Eastern group. ${ }^{29}$ When analyzing the

Table 4 Haplotype analysis in AKR1C3 for rs3763676, rs 12529 and rs7741 (in order) detected in one LD block using the Haploview 4.0 software

\begin{tabular}{lcccc}
\hline Haplotype & Cases vs controls & $\chi^{2}$ & P-value & Permuted P-value \\
\hline TGG & 0.445 vs 0.398 & 4.153 & 0.042 & 0.21 \\
CCA & 0.311 vs 0.348 & 2.857 & 0.091 & 0.34 \\
TCG & 0.231 vs 0.250 & 0.894 & 0.34 & 0.83 \\
\hline
\end{tabular}

A total of 10000 permutations were performed. groups separately, the regions on 1q23 and 10p15 could be confirmed in the Swedish families and the 8q24.1 and 18q21 regions in the Middle Eastern families.

This is the largest linkage analysis performed in familial hypospadias cases with, in total, 82 families, and 363 individuals, including 180 affected. The families are from different ethnicities, with 69 families of Swedish origin and 13 from Middle Eastern countries. Interestingly, we detected linkage in two regions (8q24.1 and 10p15) in the total material but also in different chromosomal regions in the Swedish and Middle Eastern subgroups (1q23 and 18q21). However, this may not be surprising considering the complex nature of hypospadias.

The chromosomal regions identified in our original study were large and contained hundreds of genes. ${ }^{29}$ The number of chromosomal regions has now been reduced and, therefore, the total number of potential susceptibility genes have decreased substantially, although each remaining region has not been markedly reduced. This clearly helps to focus our further studies in the search for susceptibility genes for hypospadias. The reason for the lack of confirmation of some of the peaks observed might be lack of power in our sample. However, the linkage peaks that were confirmed are likely to contain susceptibility genes with the strongest contributions to development of hypospadias in the population studied. Separate regions linked in the different subgroups confirm the complex nature of hypospadias with several different genes and environmental factors contributing. As only 13 families with Middle Eastern origin were included in the study, conclusions drawn from analysis of this subgroup should be interpreted with caution. One explanation for a separate peak in the subgroup of Middle Eastern origin, despite the small sample size, might be a genetically more homogenous population.

On the basis of chromosomal location and gene function we sequenced three genes in the $A K R 1 C$ gene family. There are four human aldo-keto reductases (AKR1C1-4) and they function in vitro as $3 \alpha$-hydroxysteroid dehydrogenase (HSD). By acting as 3-keto-, 17-keto- and 20-ketosteroid reductases, these AKRs can convert potent sex hormones (androgens, estrogen and progesterone) into their inactive metabolites. In reverse direction, however, they can produce potent hormones by oxidizing inactive or less active forms. ${ }^{39}$ Type $13 \alpha$-HSD (AKR1C4) has the highest catalytic efficiency as a 3-ketosteroid reductase and is present in the liver. ${ }^{40}$ The genes AKR1C2 ( $3 \alpha$-HSD type 3$)$ and AKR1C3 (type $23 \alpha$-HSD) are interesting for hypospadias due to the ability to form or eliminate DHT. ${ }^{39}$ Tissue distribution studies of human AKR1C3 showed a strong expression in genitourinary tissues. ${ }^{41}$ Moreover, Flück et $a l^{40}$ recently presented mutations in members of the AKR1C gene family (AKR1C2 and AKR1C4) causing 46,XY disorders of sexual development in two families,

Table 5 SNP genotyping results in the $A K R 1 C 3$ gene

Allele frequencies $(\mathrm{N})$

\begin{tabular}{|c|c|c|c|c|c|c|}
\hline Rs no (position) & Assoc. Allele & Cases & Controls & $\chi^{2}$ & $\mathrm{P}$-value & Permuted P-value \\
\hline rs1937845 (c.1-489T>C) & $\mathrm{C}$ & $0.455(272)$ & $0.400(704)$ & 5.44 & 0.02 & 0.14 \\
\hline rs10904415 (c.1-434C>T) & C & $0.673(400)$ & $0.650(1142)$ & 1.11 & 0.29 & 0.78 \\
\hline rs3763676 (c.1-138T>C) & $\mathrm{T}$ & $0.682(413)$ & $0.650(1151)$ & 1.96 & 0.16 & 0.64 \\
\hline rs12529 G > C (Gln5His) & G & $0.452(270)$ & $0.399(705)$ & 5.04 & 0.025 & 0.16 \\
\hline rs7741 $A>G$ & $\mathrm{G}$ & $0.683(411)$ & $0.650(1120)$ & 2.17 & 0.14 & 0.61 \\
\hline
\end{tabular}

$n$ : number of alleles, 10000 permutations performed. Position given in relation to translation start site. 
thus supporting the importance of this alternative pathway in the male androgen metabolism. The mutation (p.(Ala215Thr)) in our study is the first mutation of the AKR1C3 gene detected in hypospadias and the mutation is predicted to damage protein function or structure. However, none of the SNP variants identified in AKR1C2, AKR1C3 and AKR1C4 showed statistically significant associations with hypospadias.

Kruppel-like factor 6 (KLF6) is located on 10p15 and belongs to a large family of transcription factors that are associated with differentiation and tissue development including the growth of the genital tract. Microarray analysis on preputial tissue from hypospadias patients and controls showed a twofold increased expression of the KLF6 gene in cases versus controls. ${ }^{31}$ The combination of chromosomal localization and the increased expression in the skin from hypospadias boys makes this an interesting gene for hypospadias. Our sequence analysis of this gene in 95 patients and 95 controls revealed 12 genetic variants whereof one missense mutation (p.(Pro166Ser)). The patient carrying this missense mutation has a 45,X/46,XY karyotype. Individuals mosaic for a $45, \mathrm{X} / 46$, XY karyotype have a wide spectrum of phenotypes from sex reversal to hypospadias and normal males. ${ }^{42}$ This complicates the interpretation of our finding. Mutations in the KLF6 gene have earlier only been reported in association with prostate cancer. ${ }^{43,44}$ KLF6 is also connected to placenta development, which is interesting as placental dysfunction in early gestation may be a mechanism for hypospadias. ${ }^{45,46}$ Another hypothesis involves the function of KLF6 as an upregulator of ATF3, one of the novel risk genes for hypospadias. KLF6 regulates ATF3 expression by binding to and activating ATF3 promoters, thus affecting the balance between androgen and estrogen. ${ }^{47}$

In summary, we here report new chromosomal susceptibility regions for hypospadias genes based on our findings from linkage analysis and fine mapping in 82 families. Most structural mutations observed in the AKR1C2, AKR1C3, AKR1C4 and KLF6 genes in these regions appear not to be common causes for hypospadias in the Swedish and Dutch populations. Future studies should focus on finding regulatory sequences in these regions and try to replicate the (p.(Ala215Thr)) mutation in the AKR1C3 gene.

\section{CONFLICT OF INTEREST}

The authors declare no conflict of interest.

\section{ACKNOWLEDGEMENTS}

We wish to express our gratitude to all participating patients and families. We also thank Fredrik Lundberg, Christina Nyström and Johanna Lundin for excellent technical assistance. The Research Council, HRH Crown princess Lovisa Foundation, Foundation Frimurare Barnhuset Stockholm, Stockholm City Council, Swedish Society for Medical Research and Karolinska Institutet supported this work.

1 Paulozzi LJ: International trends in rates of hypospadias and cryptorchidism. Environ Health Perspect 1999; 107: 297-302.

2 Pierik FH, Burdorf A, Nijman JM, de Muinck Keizer-Schrama SM, Juttmann RE, Weber RF: A high hypospadias rate in The Netherlands. Hum Reprod 2002; 17: 1112-1115.

3 Lund L, Engebjerg MC, Pedersen L, Ehrenstein V, Norgaard M, Sorensen HT: Prevalence of hypospadias in Danish boys: a longitudinal study, 1977-2005. Eur Urol 2009; 55: 1022-1026.

4 Kallen B, Winberg J: An epidemiological study of hypospadias in Sweden. Acta Paediatr Scand Suppl 1982; 293: 1-21.

5 Fredell L, Lichtenstein P, Pedersen NL, Svensson J, Nordenskjold A: Hypospadias is related to birth weight in discordant monozygotic twins. J Urol 1998; 160(6 Pt 1): 2197-2199.
6 Akre O, Boyd HA, Ahlgren $M$ et al: Maternal and gestational risk factors for hypospadias. Environ Health Perspect 2008; 116: 1071-1076.

7 van Rooij IA, van der Zanden LF, Brouwers MM, Knoers NV, Feitz WF, Roeleveld N: Risk factors for different phenotypes of hypospadias: results from a Dutch case-control study. BJU Int 2013; 112: 121-128.

8 Bauer SB, Bull MJ, Retik AB: Empiric recurrence risk factors in urinary tract malformations: hypospadias. Birth Defects Orig Artic Ser 1979; 15: 171-180.

9 Stoll C, Alembik Y, Roth MP, Dott B: Genetic and environmental factors in hypospadias. $J$ Med Genet 1990; 27: 559-563.

10 Fredell L, Kockum I, Hansson E et al: Heredity of hypospadias and the significance of low birth weight. J Urol 2002; 167: 1423-1427.

11 Fredell L, Iselius L, Collins A et al: Complex segregation analysis of hypospadias. Hum Genet 2002; 111: 231-234.

12 Brouwers MM, van der Zanden LF, de Gier RP et al: Hypospadias: risk factor patterns and different phenotypes. BJU Int 2010; 105: 254-262.

13 Frydman M, Greiber C, Cohen HA: Uncomplicated familial hypospadias: evidence for autosomal recessive inheritance. Am J Med Genet 1985; 21: 51-60.

14 Lowry RB, Kliman MR: Hypospadias in successive generations-possible dominant gene inheritance. Clin Genet 1976; 9: 285-288.

15 Thai HT, Soderhall C, Lagerstedt $\mathrm{K}$ et al: A new susceptibility locus for hypospadias on chromosome 7q32.2-q36.1. Hum Genet 2008; 124: 155-160.

16 Morgan EA, Nguyen SB, Scott V, Stadler HS: Loss of Bmp7 and Fgf8 signaling in Hoxa13-mutant mice causes hypospadia. Development 2003; 130: 3095-3109.

17 Yucel S, Dravis C, Garcia N, Henkemeyer M, Baker LA: Hypospadias and anorectal malformations mediated by Eph/ephrin signaling. J Pediatr Urol 2007; 3: 354-363.

18 Haraguchi R, Suzuki K, Murakami R et al: Molecular analysis of external genitalia formation: the role of fibroblast growth factor (Fgf) genes during genital tubercle formation. Development 2000; 127: 2471-2479.

19 Cohn MJ, Bright PE: Molecular control of vertebrate limb development, evolution and congenital malformations. Cell Tissue Res 1999; 296: 3-17.

20 McPhaul MJ, Griffin JE: Male pseudohermaphroditism caused by mutations of the human androgen receptor. J Clin Endocrinol Metab 1999; 84: 3435-3441.

21 Thigpen AE, Davis DL, Milatovich A et al: Molecular genetics of steroid 5 alphareductase 2 deficiency. J Clin Invest 1992; 90: 799-809.

22 Geissler WM, Davis DL, Wu L et al: Male pseudohermaphroditism caused by mutations of testicular 17 beta-hydroxysteroid dehydrogenase 3. Nat Genet 1994; 7: 34-39.

23 Adamovic T, Thai HT, Lieden A, Nordenskjold A: Association of a tagging single nucleotide polymorphism in the androgen receptor gene region with susceptibility to severe hypospadias in a caucasian population. Sex Dev 2013; 7: 173-179.

24 Crescioli C, Maggi M, Vannelli GB et al: Expression of functional estrogen receptors in human fetal male external genitalia. J Clin Endocrinol Metab 2003; 88: $1815-1824$

25 Fukami M, Wada Y, Miyabayashi $\mathrm{K}$ et al: CXorf6 is a causative gene for hypospadias. Nat Genet 2006; 38: 1369-1371.

26 Beleza-Meireles A, Tohonen V, Soderhall C et al: Activating transcription factor 3: a hormone responsive gene in the etiology of hypospadias. Eur J Endocrinol 2008; 158: 729-739.

27 van der Zanden LF, van Rooij IA, Feitz WF et al: Common variants in DGKK are strongly associated with risk of hypospadias. Nat Genet 2011; 43: 48-50.

28 Bhoj EJ, Ramos P, Baker LA et al: Human balanced translocation and mouse gene inactivation implicate Basonuclin 2 in distal urethral development. Eur J Hum Genet 2011; 19: 540-546

29 Frisen L, Soderhall C, Tapper-Persson M, Luthman H, Kockum I, Nordenskjold A: Genome-wide linkage analysis for hypospadias susceptibility genes. J Urol 2004; 172(4 Pt 1): 1460-1463.

30 Penning TM, Burczynski ME, Jez JM et al: Human 3alpha-hydroxysteroid dehydrogenase isoforms (AKR1C1-AKR1C4) of the aldo-keto reductase superfamily: functional plasticity and tissue distribution reveals roles in the inactivation and formation of male and female sex hormones. Biochem $J$ 2000; 351(Pt 1): 67-77.

31 Wang Z, Liu BC, Lin GT et al: Up-regulation of estrogen responsive genes in hypospadias: microarray analysis. J Urol 2007; 177: 1939-1946.

32 Kong A, Gudbjartsson DF, Sainz J et al: A high-resolution recombination map of the human genome. Nat Genet 2002; 31: 241-247.

33 Gudbjartsson DF, Jonasson K, Frigge ML, Kong A: Allegro, a new computer program for multipoint linkage analysis. Nat Genet 2000; 25: 12-13.

34 Lander E, Kruglyak L: Genetic dissection of complex traits: guidelines for interpreting and reporting linkage results. Nat Genet 1995; 11: 241-247.

35 Barrett JC, Fry B, Maller J, Daly MJ: Haploview: analysis and visualization of LD and haplotype maps. Bioinformatics 2005; 21: 263-265.

36 Spielman RS, McGinnis RE, Ewens WJ: Transmission test for linkage disequilibrium: the insulin gene region and insulin-dependent diabetes mellitus (IDDM). Am J Hum Genet 1993; 52: 506-516

37 Ramensky V, Bork P, Sunyaev S: Human non-synonymous SNPs: server and survey. Nucleic Acids Res 2002; 30: 3894-3900.

38 Ng PC, Henikoff S: SIFT: Predicting amino acid changes that affect protein function. Nucleic Acids Res 2003; 31: 3812-3814.

39 Penning TM, Jin Y, Steckelbroeck S, Lanisnik Rizner T, Lewis M: Structure-function of human 3 alpha-hydroxysteroid dehydrogenases: genes and proteins. $\mathrm{Mol} \mathrm{Cell}$ Endocrinol 2004; 215: 63-72. 
40 Flück CE, Meyer-Boni M, Pandey AV et al: Why boys will be boys: two pathways of fetal testicular androgen biosynthesis are needed for male sexual differentiation. Am J Hum Genet 2011; 89: 201-218.

41 Azzarello J, Fung KM, Lin HK: Tissue distribution of human AKR1C3 and rat homolog in the adult genitourinary system. J Histochem Cytochem 2008; 56: 853-861.

42 Cools M, Pleskacova J, Stoop H et al: Gonadal pathology and tumor risk in relation to clinical characteristics in patients with 45,X/46,XY mosaicism. J Clin Endocrinol Metab 2011; 96: E1171-E1180

43 Narla G, Difeo A, Reeves HL et al: A germline DNA polymorphism enhances alternative splicing of the KLF6 tumor suppressor gene and is associated with increased prostate cancer risk. Cancer Res 2005; 65: 1213-1222.
44 Bar-Shira A, Matarasso N, Rosner S, Bercovich D, Matzkin H, Orr-Urtreger A: Mutation screening and association study of the candidate prostate cancer susceptibility genes MSR1, PTEN, and KLF6. Prostate 2006; 66: 1052-1060.

45 Fujimoto T, Suwa T, Kabe K, Adachi T, Nakabayashi M, Amamiya T: Placental insufficiency in early gestation is associated with hypospadias. J Pediatr Surg 2008 43: 358-361.

46 van der Zanden LF, van Rooij IA, Feitz WF, Franke B, Knoers NV, Roeleveld N: Aetiology of hypospadias: a systematic review of genes and environment. Hum Reprod Update 2012; 18: 260-283.

47 Huang X, Li X, Guo B: KLF6 induces apoptosis in prostate cancer cells through up-regulation of ATF3. J Biol Chem 2008; 283: 29795-29801. 